\title{
Impact of Electrocatalytic Activities of Doping Surfactants on Polyaniline as Pt-free Counter Electrode in DSSCs
}

\author{
Kezhong Wu, Qiongwei Zhao, Lei Chen, Bei Ruan, Mingxing Wu \\ Key Laboratory of Inorganic Nano-materials of Hebei Province, Department of Chemistry and \\ Material Science, Hebei Normal University, Shijiazhuang, 050024, P.R. China \\ *E-mail: wukzh688@163.com
}

doi: $10.20964 / 2018.05 .67$

Received: 24 January 2018 / Accepted: 13 March 2018 / Published: 10 April 2018

\begin{abstract}
A series of composite counter electrodes were chemically synthesized by doping surfactants with, Ganodermalucidum Polysaccharide (GLP), Sodium dodecyl sulfate (SDS) and Ethylenediaminetetraacetic acid (EDTA) disodium salt on polyaniline (PANI) for Dye-sensitized solar cells (DSSCs). Surfactants can reduce the surface tension of the liquid, along with changing the conductivity and morphology of PANI. Scanning electron microscopy (SEM) results showed that PANI electrode morphology was strongly influenced by the surfactant. The electrochemical activity of surfactant-doping PANI was investigated by cyclic voltammetry (CV) curve, electrochemical impedance spectroscopy (EIS), Tafel polarization curve and current density-voltage curves $(J-V)$. The power conversion efficiency (PCE) of PANI-doped CEs with additions of SDS, GLP and EDTA disodium salt $(4.25 \%, 2.69 \%$ and $2.51 \%)$ were higher than $2.29 \%$ for PANI CE without doping. These results indicate a potential application of surfactants doped polyaniline as counter electrode in costeffective DSSCs.
\end{abstract}

Keywords: Dye-sensitized solar cells; Counter electrode; Polyaniline; Surfactant; Power conversion efficiency

\section{FULL TEXT}

(c) 2018 The Authors. Published by ESG (www.electrochemsci.org). This article is an open access article distributed under the terms and conditions of the Creative Commons Attribution license (http://creativecommons.org/licenses/by/4.0/). 